\title{
An assessment of consumers' subconscious responses to frontline employees' attractiveness in a service failure and recovery situation
}

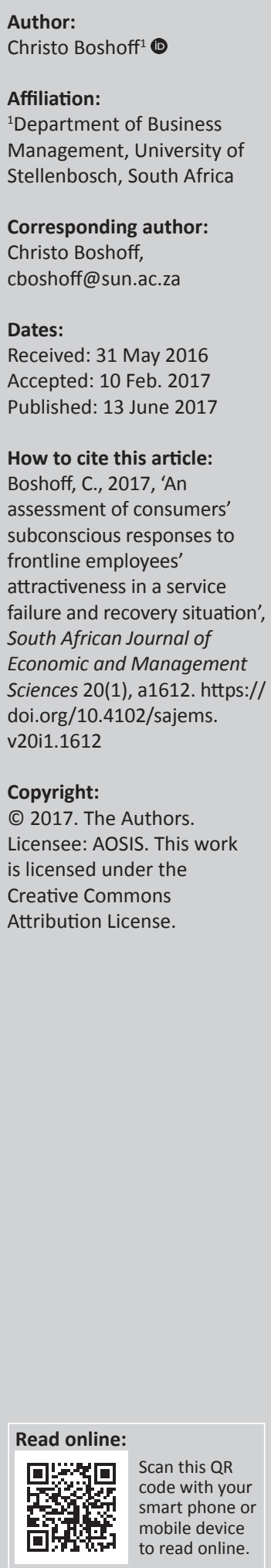

Background: Initial analyses of the impact of physical attractiveness in a business context have supported the 'what is beautiful is good' contention. However, in circumstances characterised by negative emotions, duress and stress, very little is known about how human beings respond at the subconscious level to the attractiveness of frontline service providers.

Aim: The purpose of this study was to assess whether consumers who complain to a frontline service provider about a service failure respond differently at the subconscious level when the service provider involved in the service encounter is attractive compared with one who is less attractive.

Method: Forty respondents were exposed to a video clip of a service failure and service recovery situation. While viewing the hypothetical scenario, two neuro-physiological measurements were used to collect data at the subconscious level, namely galvanic skin response (GSR) and electroencephalography (EEG).

Results: The results suggest that, at the subconscious level, customers respond differently to the service recovery efforts depending on the attractiveness of the frontline service provider who attempts to rectify the service failure.

Conclusion: The results seem to suggest that the physical attractiveness of a frontline service provider moderates (or softens) the negative emotions that a complaining customer might experience during a service failure and complaint situation - consistent with the "what is beautiful is good' contention.

\section{Introduction}

Marketers, based on the principles of environmental psychology (Bechel \& Churchman 2002), acknowledge that the environment in which marketing interactions - such as a service encounter - take place influence all those involved in the interaction (Bitner 1990, 1992). In a service delivery context, Sundaram and Webster (2000:380) conceptualise the service environment in a communication paradigm by referring to the verbal and non-verbal communication cues the environment transmits. Their conceptual model indicates that both forms of communication (verbal and non-verbal) between a frontline service provider and a customer influence the consumer's feelings, which then influence their evaluation of the service encounter. An important element of the non-verbal communication in the model is the physical appearance of employees (Sundaram \& Webster 2000:380).

Although the scholarly interest in people's physical appearance can be traced back to the 1920s (Rumsey 2008), it was not until the 1960s that researchers such as Walster et al. (1966) started systematically to investigate the role that the physical attractiveness of people plays in influencing others' perceptions and attitudes (Feingold 1992; Landy \& Sigall 1974). Before that, many psychologists found the idea that others can be judged by their appearance 'unpalatable' (Kleinke 1974).

Initially, the consensus was that those who are physically attractive, particularly with very few other cues at their disposal, are more likely to be associated with favourable outcomes such as social acceptance. Attractive people were rated as having better career prospects, expected to be more competent spouses and expected to have happier social and professional lives (Dion, Berscheid \& Walster 1972). The 'what is beautiful is good' contention was confirmed in a variety of studies (Dion et al. 1972:285). These results led Berscheid (1981) to conclude that physical 
attractiveness is an 'extraordinarily important psychological variable' that leads to a variety of favourable outcomes for those who possess those characteristics.

However, Bull and Rumsey (1988) argued that Berscheid (1981) had overstated the importance of physical attractiveness, and they were particularly critical of the methodologies used in many of the studies on which those conclusions were based. In the majority of these studies, undergraduate students were used as subjects, the stimuli were often limited to head-and-shoulder photographs and they expressed concern about the ecological validity of some of the experiments.

Closer scrutiny in later years by Feingold (1992) and others suggested that these 'positives' associated with attractiveness are more likely to be limited to social contexts (popularity and more friends, lower social anxiety) and favourable evaluations of 'soft skills' such as persuasion (Chaiken 1979). The impact of physical attractiveness was far less influential in situations where the attractive person was associated with cognitive skills and competencies, and 'near zero' for character-like traits such as integrity and concern for others (Eagly et al. 1991; Feingold 1992). In other words, the generalisability of the attractiveness-ability relationship was strongly questioned.

Although the initial thrust of this stream of research on the impact of physical attractiveness was grounded in psychology, marketers have increasingly shown an interest in the impact that the physical attractiveness of employees can have on variables of interest to them. These include the effectiveness of product endorsers (Kahle \& Homer 1985), advertising effectiveness (Baker \& Churchill 1977), salesperson performance (Ahearne, Gruen \& Jarvis 1999) and customer satisfaction (Söderlund \& Julander 2009).

Service managers have also become interested in the influence of the physical appearance of service delivery staff. Because service delivery and consumption often occur simultaneously (Bitner 1990), and given that the role of frontline employees is crucial in customer perceptions of service quality and satisfaction (Bitner, Booms \& Tetreault 1990), service marketers are particularly interested in the appearance of their employees.

The seminal work of Bitner $(1990,1992)$ on the impact of physical surroundings, including the appearance of frontline staff, has shown that the physical appearance of service providers strongly influences customers' evaluations and perceptions in a service delivery context. However, we know that consumer responses and decisions are not based entirely on so-called rational thinking only. Those responses and decisions hinge on both reason and emotion, and it is estimated that up to $95 \%$ of human thinking takes place in the subconscious mind (Zaltman 2003). However, humans are often not able to articulate their feelings and thinking because they occur below the perceptual level (Zurawicki 2010) - yet these feelings and thinking drive their decisions and responses (Kagan 2002). Unfortunately, marketing researchers often do not adequately explore what consumers cannot articulate. Consumers share only the logical aspects of their responses and decision-making, as these are much easier to convey than their subconscious emotions. As a result, as Zaltman and Zaltman (2008) point out, researchers only explore at the surface level of what consumers think, and this bias often produces invalid responses. Given the fact that consumer responses and decision-making are strongly influenced by the social and physical contexts they find themselves in at the time of the decision-making (Lowenstein 2001), which service encounters inevitably are, this study explored consumers' subconscious responses in a service encounter context.

No research has been done to assess whether the physical attractiveness of service providers can play a role in an emotion-laden situation such as service failure-customer complaint interaction. Using neuro-physiological measurement to measure subconscious emotional responses when collecting the data overcomes many of the methodological limitations of earlier studies. Against this background, the primary purpose of the study was to assess whether customers who complain to a service provider about a service failure respond differently at a subconscious level when the service provider involved in the service encounter is attractive rather than one who is less attractive.

\section{The service encounter}

A service encounter - including a customer complaint encounter, which is the focus of this study, can be characterised in terms of social exchange theory, as it contains all of the basic components of the theory, namely actors, access to resources, exchange structures and a process of exchange (Molm 2006). Consistent with social exchange theory, the actors in a dyadic service encounter act in their own selfinterest to maximise the advantages of the outcome of the encounter. Both the service provider and the customer have access to resources: the customer's future patronage is of value to the service provider, while the service provider has the ability and resources to address the complaining customer's problem or complaint. Both actors, thus, depend on each other to some extent to ensure what Molm (2006) refers to as 'positive value' from the exchange (resolution of the complaint for the customer and loyalty for the service provider) and to minimise the negative value (such as financial loss and loss of time). This mutual dependence or structure is a key component of social exchange theory. Finally, a service encounter provides a process of exchange in which the benefits any party receives during the exchange are contingent on the benefits the other party receives. In a service complaint-resolution situation, a service provider will only address the complaint if he or she feels the customer will, as a result, remain in the relationship; and the complaining customer will only remain in the relationship if the problem or complaint is addressed. In other words, both parties will exchange value if there are sufficient benefits for both of them. 
How the service encounter is experienced is, however, not only largely determined by the behaviour of frontline employees (Sergeant \& Frenkel 2000) but is also strongly influenced by the emotional responses of both the employees (Hennig-Thurau et al. 2006; Slatten 2011) and the customers (Harris \& Ogbonna 2006; McColl-Kennedy et al. 2009). Those emotions can be influenced by both verbal communication and physical cues (Dallimore, Sparks \& Butcher 2007; Sundaram \& Webster 2000).

\section{The role of physical features}

Social psychologists are interested in consumers' physical features (mainly their demographics) because they believe a person's physical appearance is generally the first piece of information available to them when meeting a stranger (Dion et al. 1972), and the interpretation of those features will strongly influence the subsequent assessment of the person (Hogg \& Vaughan 2008). Social categorisation theory suggests that this assessment leads to group identification (attractive people in this case) or rejection of the group in an attempt to reduce subjective uncertainty about the person.

Although a person's appearance is concrete and directly observable, it is often linked to traits such as honesty and sincerity, which are often based only on inference (Park 1986). These inferences influence human feelings (affect, emotions and mood) and, as a result, their decision-making process too (Hogg \& Vaughan 2008). However, although human beings will cognitively evaluate a situation (which includes the physical appearance of a person in a dyad such as a service encounter), this evaluation is normally followed by both an affective and a physiological response. The affective component of such a response (the emotion) is largely autonomic and can be described in one of two terms: either 'harm' (characterised by negative emotions such as fear, resulting in avoidance behaviour) or 'benefit' (evoking positive emotions such as happiness, leading to approach behaviour). This emotional response influences thought, judgement and subsequent behaviour (Bitner 1992; Kardes \& Cronley 2000). In other words, what consumers actually see during an interaction will impact their responses and their subsequent evaluation of the encounter, (dis)satisfaction and behaviour (such as buying or not buying). For instance, Söderlund and Julander (2009) have empirically demonstrated that, when customers interact with an attractive airline stewardess, their assessment of her attractiveness influences their assessment of the employee, which spills over into a positive impact on customer satisfaction.

\section{The nature of human attractiveness}

Attractiveness can be seen as a socially valued characteristic in the same category as intelligence, charm or athletic ability (Feingold 1992). The evaluative meaning of what is regarded as attractive is based on two sources (Eagly et al. 1991): direct observation in one's social environment and exposure to cultural representations of 'attractive' and 'unattractive' people. The former is strongly influenced by how others respond to attractive people and how they are treated by their peers. These perceptions lead to a social consensus about what is regarded as beautiful or attractive (Berscheid \& Walster 1974).

In a marketing context, Ahearne et al. (1999) define attractiveness as the extent to which a customer perceives an employee (such as a salesperson or, in this study, a service provider) as possessing an appealing and pleasing physical appearance.

\section{The impact of attractiveness}

In a marketing context, attractiveness has proved both influential and beneficial. A meta-analysis of the impact of source effects, of which physical attractiveness was one, has shown that physical attractiveness does impact the persuasiveness of interpersonal communication (Wilson \& Sherrell 1993). Attractive spokespersons, advertising models and salespeople have, compared with less attractive ones, been shown to be more persuasive, producing more positive product evaluations and better recall, and are more likely to influence purchasing intentions (Chaiken 1979; DeShields, Kara \& Kaynak 1996; Joseph 1982; Kahle \& Homer 1985; Reingen \& Kernan 1993). The attractiveness stereotype proved particularly influential in the absence of other cues such as perceived expertise (Joseph 1977), especially when used 'appropriately'. The latter refers to the role of attractiveness in the 'right' product categories, consistent with the so-called 'match-up' hypothesis (Baker \& Churchill 1977; Kamins 1990). In an advertising context, the match-up hypothesis argues that there needs to be congruence between the person (such as an endorser of a product) used in an advertisement and the product being advertised.

The research on the impact of physical attractiveness in a marketing context reveals two major caveats. Firstly, the impact of the gender of the person assessing physical attractiveness has not been adequately explored. This is surprising if one considers the fact that differences in how males and females process information and make decisions have been reported. For instance, male consumers are typically more independent decision-makers, and female consumers are more interdependent (Meyers-Levy \& Loken 2015). In an advertising context, it has been demonstrated that different genders respond differently, for instance, to advertisements (Putrevu 2004) and to the perceived effectiveness of advertising (Noble, Pomering \& Johnson 2014). Differences have also been reported at the subconscious level (Spalek et al. 2015). Music psychologists have demonstrated that emotions evoked by music differ between males and females: females typically have a stronger response than males towards an arousing and unpleasant musical stimulus (Nater et al. 2006).

The manipulation of gender in this study was also based on the contention that the attractiveness stereotype is more prevalent among females than among males (Bar-Tal \& Saxe 1976; Eagly et al. 1991; Reingen \& Kernan 1993). For instance, Jackson, Sullivan \& Rostker (1988) reported that females, 
compared with males, rated physical attractiveness as more important to them and that they do more to look attractive than their male counterparts.

The second caveat is the fact that almost all of the empirical results related to the impact of physical attractiveness reviewed here have been based on perceptual data respondents basing their evaluations on how 'successful' (depending on the context and the dependent variable under investigation) they expect the attractive target to be. The only exception was Ahearne et al. (1999), who used actual sales data as the dependent variable and found a positive relationship between physical attractiveness and successful selling. However, the strength of the relationship weakens over time.

Although attractiveness on a cognitive level has been investigated in the psychology and sociology literatures, the emotional impact of attractiveness has not received much attention (Friedman, Riggio \& Casella 1988) since the seminal study of Mehrabian and Blum (1997). They reported a link between the emotions reported by their respondents and the ratings of humans' physical attractiveness. For instance, faces that produced feelings of pleasure, arousal and submissiveness were judged as attractive, while those that elicited feelings of displeasure, low arousal and dominance over others were considered unattractive (Mehrabian \& Blum 1997). Unfortunately, they, like most others who have investigated emotional states in marketing contexts, relied on pencil-and-paper tests to 'measure' emotions.

Pencil-and-paper measures of emotional states may be problematic, as humans often try to regulate their emotions (Zeelenberg et al. 2008), and as a result, when self-report tests are used to 'measure' emotional states, social desirability bias is often a source of concern (Paulhus \& John 1998). Another source of concern is the fact that self-reports are often retrospective in nature and rely on the person's post hoc, cognitive interpretation of their own mental or behavioural responses (Cacioppo 2002). Unfortunately, not all people have the same ability or willingness to report their emotional states effectively (Mauss \& Robinson 2009).

Studies conducted on attractiveness are also, from a methodological perspective, not beyond reproach. The empirical research conducted mainly by social psychologists has collected data by one of two means: either by a self-rating of attractiveness, or by respondents (often referred to as 'perceivers') being asked to rate a target's attractiveness on a perceptual scale (e.g. Walster et al. 1966), and the attractiveness score is then the mean scores of multiple raters (Feingold 1992), usually after exposure to a photograph or photographs.

Despite the clear importance of the physical appearance of frontline service delivery personnel, very few studies have addressed the role of physical attractiveness in a service encounter context, despite calls to investigate the relationship (Söderlund \& Julander 2009). In one of the few exceptions, Koernig and Page (2002) investigated the match-up hypothesis in a dentist service encounter environment and found that the attractiveness of a service provider must be consistent with the image of the service if it is to be influential. Söderlund and Julander (2009) did investigate the role of physical attractiveness in a service encounter, but used photographs as experimental stimuli and collected perceptual data to measure satisfaction. The current study overcame many of these methodological limitations by assessing the subjects' subconscious responses to attractiveness or unattractiveness by measuring their neuro-physiological responses.

\section{The value of neuro-physiological measurement}

Psychologists such as Uleman and Bargh (1989) and Zaltman (2003) have shown that a fair amount of mental processing is subconscious in nature. Human beings and their decisionmaking are strongly influenced by emotions, they often think in an automated manner, and many motivations and behaviours are not consciously 'controlled'.

Neuroscience measures consumers' subconscious and emotional responses that are not controlled by the central nervous subsystems (which is what happens when a selfreport type test is used). This 'observation-like' approach to data collection prevents the subjects from cognitively rationalising their decisions and largely avoids the risk of false and inaccurate self-reports (LaBarbera \& Tucciarone 1995:37). The benefits of this methodology are that researchers better understand consumer choice and decisionmaking (Vartanian \& Mandel 2011). This contention is particularly true when consumers experience responses that they cannot explain themselves, are unaware of, or prefer to hide. In these circumstances, this neuro-physiological measurement methodology is able to enhance the validity of empirical results.

\section{Objectives}

The primary purpose of the study was to assess whether customers who complain to a service provider about a service failure respond differently at a subconscious level when the service provider involved in the service encounter is attractive than when the person is less attractive. The purpose was, thus, to investigate whether the 'what is beautiful is good' contention also holds at the subconscious level - and more specifically, when the person complaining experiences negative emotions such as stress and anxiety, which service failures inevitable provoke (Chebat \& Slusarczyk 2003; Tronvoll 2011). A secondary objective of the study was to assess whether these subconscious responses are influenced by a gender-effect.

\section{Hypotheses and propositions}

Social exchange theory predicts that both parties in a dyadic service encounter will try to maximise their obtained benefit from the interaction. From a customer perspective, this 
benefit will be to maximise satisfaction with the outcomes of the encounter. But if goal attainment is threatened, a negative emotional response is the likely consequence (Lazarus 1999). However, based on social categorisation theory (Tajfel 1981), we know that when a customer enters a service encounter, the human brain will almost automatically classify the other party as either attractive or not attractive (Gulas \& McKeage 2000), which may influence how the customer will respond. The empirical results reported by Söderlund and Julander (2009), that the satisfaction of a customer in a service encounter is mediated by their perception of the attractiveness of the service provider, suggest that the attainment of the desired benefit could be enhanced or reduced by responses to the physical features of the service provider. These responses can be both conscious-cognitive responses and subconscious emotional responses (Zaltman 2003).

Based on the general tone of the 'what is beautiful is good' literature (DeShields et al. 1996; Dion \& Stein 1978; Mehrabian \& Blum 1997; Reingen \& Kernan 1993), the theoretical model of Sundaram and Webster (2000), the empirical evidence that gender impact on how information is processed subconsciously (Spalek et al. 2015) and the empirical findings specifically related to a service encounter (Söderlund \& Julander 2009), the following hypotheses and propositions are addressed:

$\mathrm{H}^{1}$ : Service recovery by an attractive opposite-gender service provider will not lead to negative subconscious responses among males.

$\mathrm{H}^{2}$ : Service recovery by a less attractive opposite-gender service provider will not lead to negative subconscious responses among males.

$\mathrm{H}^{3}$ : Service recovery by an attractive opposite-gender service provider will not lead to negative subconscious responses among females.

$\mathrm{H}^{4}$ : Service recovery by a less attractive opposite-gender service provider will not lead to negative subconscious responses among females.

$\mathrm{P}^{1}$ : Service recovery by an opposite-gender attractive male service provider will not produce more positive subconscious responses than a less attractive male service provider among female complainers.

$\mathrm{P}^{2}$ : Service recovery by an opposite-gender attractive female service provider will not produce more positive subconscious responses than a less attractive female service provider among male complainers.

Based on the often-cited concern about social desirability bias in research (Zikmund 2003:183) and the argument that neuro-physiological research overcomes this potential bias (LaBarbera \& Tucciarone 1995:37) because skin conductance changes and brain activity are not under the control of the central nervous system, a further research question was considered: Do complaining customers suppress their (negative) emotional responses following a service failure when asked to express a cognitive assessment of the service failure and recovery experience?

\section{Methodology Stimuli}

The context of this study was a hypothetical airline service failure and recovery scenario. The airline industry was selected because it allows the creation of realistic hypothetical service failure and recovery situations (enhancing the external validity of the study) and has been used in several previous service failure recovery studies (Harris et al. 2006; Lorenzoni \& Lewis 2004).

In this study, only facial attractiveness was investigated primarily because it is a more influential attribute than bodily attractiveness (Mehrabian \& Blum 1997) and also to avoid the risk that the inclusion of bodily attractiveness could have confounded the empirical results.

Subjects' subconscious responses were recorded while watching a realistic service failure and recovery scenario (video) lasting about 2 min rather than the static, single photographs in association with text-based vignettes that were used in earlier research. The former adds an element of external validity absent in many previous studies.

As frontline service providers can respond in a variety of ways in a service failure and customer complaint situation (e.g. angrily, denying responsibility, unhelpful), the service providers' response to the complaint was held constant in all scenarios. Following the complaint, the service provider in each hypothetical scenario offered an explanation for the service failure, accepted blame on behalf of the airline, apologised, offered a resolution (I will make sure that your luggage is delivered to your home tomorrow), offered compensation (a free airline ticket) and expressed their appreciation for the passenger's custom with the airline. The scenario is, thus, characterised by a non-confrontational attitude from the service provider.

Because a person's physical appearance and gender classification are the personal characteristics that are most obvious and accessible to others in social interaction (Berscheid \& Walster 1974), physical attractiveness and gender were manipulated in this study.

In addition, consistent with Saad's (2004) contention that assessments of physical attractiveness are influenced by an opposite-gender effect, we tested only opposite-gender responses in this study (e.g. female respondents watching video clips with only male service providers handling the complaint). In this way, we controlled for the oppositegender effect in attractiveness assessments.

\section{Neuro-physiological measurement}

In this study, two neuro-physiological measures were used to assess the Arousal and the Valence of responses when exposed to service recovery scenarios by both attractive and less attractive service providers. These measures were galvanic skin response (GSR) and electroencephalography (EEG). 


\section{Galvanic skin response}

Electrodermal activity refers to changes in the electrical conductance of the skin due to changes in moisture levels (Van Praet 2012:22). These changes are the result of changes to the eccrine (sweat) glands in the human skin and are regulated by the autonomic nervous subsystems. Changes in electrical activity are the result of physiochemical changes and are, therefore, an indication of emotional arousal. Because humans have no control over their autonomic nervous systems, these electrodermal responses (as the glands dilate) are indications of activation or arousal in response to stimuli that human beings cannot control (Venkatraman et al. 2015).

Galvanic skin response measures only arousal, it has a base level of zero, and therefore, cannot be a negative value. In other words, the higher the index, the stronger the level of arousal.

\section{Electroencephalography}

Electroencephalography measures the amplitude of cerebral waves or brain activity in response to the exposure to some form of stimulus such as viewing a product, packaging or an advertisement or, as in this study, as a customer moves through a service encounter. What makes this data collection method particularly suitable for studies of this nature is its high temporal resolution. EEG is capable of recording data in sub-millisecond intervals, while alternative methodologies, such as functional magnetic resonance imaging (fMRI), have a resolution time of several seconds (Ohme et al. 2010).

In this study, frontal asymmetry was measured by means of EEG, and specialised procedures and algorithms were used to control individual differences in the baseline cortical activation. The EEG measurement used 32 electrodes on each subject's scalp according to the 10-20 electrode placement system. The electrodes were placed in a bipolar fashion, as proposed by Cacioppo, Tassinary and Berntson (2000).

\section{Pre-test}

As the literature confirms, beauty is in the eye of the beholder. The manipulation of the attractiveness of the service provider in the service recovery scenarios thus had to be empirically confirmed. Consistent with previous studies (Koernig \& Page 2002; Reingen \& Kernan 1993), a single-item, semantic differential scale anchored by very attractive (scored as 10) and very unattractive (scored as 1) was used by a sample of 44 respondents to rate each actor in the hypothetical service failure and recovery scenario. Using the mean scores across all participants, a paired sample $t$-test revealed that the expected attractive male and female actors were rated significantly more attractive than the less attractive actors $($ males $t$-value $=11.66 ; p<0.00$ and females $t$-value $=14.01$; $p<0.00)$. These results suggest that the manipulation of attractiveness was effective.

\section{Data collection}

The research design of this study can be described as a laboratory experiment, although the data were collected by means of electronic observation. Each subject was exposed to exactly the same scenarios in the form of a video clip illustrating a hypothetical service failure and recovery situation involving an airline. The only exception was the manipulation of the physical appearance of the airline agent (attractiveness and gender). The words used in the scenario (in the video clip) are provided in Appendix 1. These words, expressed by the complaining customer only, were scrolled across the screen to control for the influence of tone of voice.

The voices of the actors (service providers) during the service encounter were, however, their own. Although the actors (service providers) were instructed to use a consistent, monotone-like tone of voice devoid of any emotion, the differences in the tone of voice could not be controlled for. Similarly, the actors (service providers) were instructed to keep their facial expressions neutral and not to exhibit any expressions that might reflect an emotional response.

The nature of the service provider-customer interaction can be described as an airline traveller, who has just disembarked, complaining to an agent of the airline about lost luggage after a transatlantic flight.

The video clip consists of an opening scene of a commercial aeroplane landing at a national airport (shot on location), passengers disembarking, and then walking towards a rolling carousel full of luggage. This is followed by a shot of an empty carousel, and the camera then moving towards the luggage handling kiosk. The kiosk is 'neutral' in the sense that there is no branding or logo of any actual airline. The focus of the camera is then on the service provider while the passenger's words of complaint are scrolled across the screen (Good morning. I have just arrived on flight 221 from New York via London. My luggage is not on carousel 1 as you announced, or on any other carousel for that matter. Can you please establish what happened to my luggage?). The service provider then addresses the complaint by responding in his or her own voice, as described in Appendix 1.

Four hypothetical service failure and service recovery scenarios were created in the form of video clips lasting slightly more than 2 min each: one attractive male, one less attractive male; one attractive female, one less attractive female. Each participant, however, viewed only oppositegender scenarios. After viewing each of the two oppositegender video scenarios, the respondents were asked one question about their satisfaction with how they were treated by the airline agent: 'If you were the passenger in this video clip, how satisfied would you be with the way the airline handled your complaint?'. The question was linked to a bipolar semantic differential scale anchored by very satisfied (5) to very dissatisfied (1).

Exposure to the scenarios (including distracters) was counterbalanced and presented in random order. The 
purpose of distractors is temporarily to occupy the cognitive processes and to 'reboot' the working memory of respondents. This task requires a higher cognitive load and allows respondents to focus on something other than the main purpose of the study without being exposed to emotionally loaded content. The only task expected of the subjects was to watch the stimuli presented on the screen. Buffer assignments (a cognitively engaging task - e.g. fragments of the Stroop test) were used. Within-subject designs are common in these types of studies (Hazlett \& Hazlett 1999), and all subjects were exposed to the stimuli individually.

Before being exposed to each scenario, a baseline was measured for $30 \mathrm{~s}$. Before the test started, the subjects were told that they had to pretend that they were the complaining customer in the scenario.

\section{The sample}

The group of 40 subjects consisted of 20 males and 20 females drawn on a convenience basis from a panel of volunteers. The sample size compares favourably with others that have done similar studies (Boksem \& Smidts 2015 - 32 subjects; Plassman \& Weber 2015 - 20 subjects). The subjects were all aged between 20 and 45 years and had travelled on a commercial airline at least once before.

\section{Empirical results Neuro-physiology measurement results}

Table 1 summarises the GSR indices, which are indications of activation or arousal in response to the scenario stimuli. It shows that - regardless of the gender of the respondent and the physical features of the frontline service provider the arousal of the respondent is significantly above the baseline in all four instances. However, it is noticeable that the female GSR indices are higher than those of the male respondents when dealing with the opposite gender. The results reported in Table 1, thus, provide some evidence of a gender effect at the subconscious level. It must also be noted that the GSR responses (arousal) are higher for the less attractive service provider for both genders (1.83 in the case of females and 1.32 in the case of male respondents). It thus appears as if, at the subconscious level, there is some evidence of an attractiveness bias. Unfortunately, the GSR scores do not indicate valence; and so the subconscious responses to the service recovery situations were further explored using EEG measures.

Table 2 shows that all of the EEG responses are negative compared with the baseline, regardless of whether or not the service provider handling the complaint is attractive. However, only one response is statistically significantly different from the baseline, and that is when male respondents deal with the less attractive female service provider $(t=-3.22$; $p<0.01$ ). $\mathrm{H}^{2}$ must, thus, be rejected (in respect of the less attractive service provider). However, $\mathrm{H}^{1}$ cannot be rejected (in respect of the attractive service provider). Hypotheses $\mathrm{H}^{3}$ and $\mathrm{H}^{4}$ can both not be rejected, as the relative attractiveness
TABLE 1: Galvanic skin response results.

\begin{tabular}{lllll}
\hline Respondents & GSR index & $\boldsymbol{t}$-value & Probability & $\boldsymbol{d} \boldsymbol{f}$ \\
\hline Male & & & & \\
More attractive female service provider & 1.22 & 3.56 & $p<0.01$ & 18 \\
Less attractive female service provider & 1.32 & 3.20 & $p<0.01$ & 18 \\
Female & & & & \\
More attractive male service provider & 1.49 & 4.81 & $p<0.00$ & 19 \\
Less attractive male service provider & 1.83 & 5.66 & $p<0.00$ & 19 \\
\hline
\end{tabular}

GSR, galvanic skin response, $d f$, degrees of freedom.

TABLE 2: Electroencephalography results.

\begin{tabular}{lllll}
\hline Respondents & EEG index & $\boldsymbol{t}$-value & Probability & $\boldsymbol{d f}$ \\
\hline Male & & & & \\
More attractive female service provider & -0.34 & -1.84 & n.s. & 16 \\
Less attractive female service provider & -0.49 & -3.22 & $p<0.01$ & 16 \\
Female & & & & \\
More attractive male service provider & -0.03 & -0.21 & n.s. & 17 \\
Less attractive male service provider & -0.14 & -0.93 & n.s. & 17 \\
\hline
\end{tabular}

EEG, electroencephalography; $d f$, degrees of freedom; n.s., not significant.

of the service provider does not seem to influence the subconscious responses of the female subjects.

A cursory glance at the EEG indices in Table 2 does seem to suggest that male respondents are a lot harsher in their subconscious responses to the recovery efforts than females, but that they are particularly displeased with the efforts of the less attractive service provider, despite the fact that the service provider accepted responsibility, apologised and offered the customer some compensation. The results reported in Table 2, thus, provide further evidence of a gender effect at the subconscious level as well as evidence supporting the attractiveness bias.

It is also notable that the EEG values (in Table 2) for the more attractive service providers are consistently better (less negative) than for the less attractive service provider, regardless of the gender of the respondent. In the case of female respondents, it is -0.14 for the less attractive male service provider, compared with only -0.03 for the more attractive service provider (a difference of 0.11 ). In the case of the male respondents, the scores are -0.49 and -0.34 , respectively (a difference of 0.15 ). These results seem to suggest that, at the subconscious level, the attractiveness bias is influenced by gender. Based on the results reported in Table 2, Propositions 1 and 2 must be rejected.

In Table 3, the EEG responses of the male respondents are analysed per individual scene (see Appendix 1) during the service recovery encounter. When 'interacting' with the less attractive female service provider, the EEG indices of the male participants are consistently negative (right pre-frontal activation), suggesting avoidance behaviour. The EEG index deviates from the baseline to a significant extent when the less attractive service provider offers an explanation $(p<$ $0.01)$, when she accepts blame for the lost luggage $(p<0.001)$, when offering compensation $(p<0.10)$ and when expressing appreciation for the traveller's custom $(p<0.10)$. When the less attractive service provider apologises for the poor service delivery and offers a resolution (I will make sure that your 
TABLE 3: Male respondents: Less attractive female service provider.

\begin{tabular}{lllll}
\hline Scene & EEG index & $\boldsymbol{t}$-value & $\boldsymbol{p}$-value & $d f$ \\
\hline Explanation & -0.54 & -2.93 & $0.01^{* *}$ & 16 \\
Accept blame & -0.86 & -3.30 & $0.00^{* * *}$ & 16 \\
Apologising & -0.46 & -1.72 & 0.11 & 16 \\
Resolution & -0.39 & -1.65 & 0.12 & 16 \\
Compensation & -0.41 & -2.00 & $0.06^{*}$ & 16 \\
Appreciation & -0.37 & -2.10 & $0.05^{*}$ & 16 \\
\hline
\end{tabular}

${ }^{*} p<0.10 ; * * p<0.01 ; * * * p<0.001$.

$\mathrm{EEG}$, electroencephalography; $d f$, degrees of freedom.

TABLE 4: Male respondents: More attractive female service provider.

\begin{tabular}{lllll}
\hline Scene & EEG index & $\boldsymbol{t}$-value & $\boldsymbol{p}$-value & $\boldsymbol{d f}$ \\
\hline Explanation & -0.37 & -1.40 & 0.18 & 16 \\
Accept blame & -0.35 & -1.30 & 0.21 & 16 \\
Apologising & -0.42 & -1.63 & 0.12 & 16 \\
Resolution & -0.25 & -0.95 & 0.36 & 16 \\
Compensation & -0.61 & -3.13 & $0.01^{*}$ & 16 \\
Appreciation & -0.37 & -1.85 & 0.08 & 16 \\
\hline
\end{tabular}

$*, p<0.01$.

EEG, electroencephalography; $d f$, degrees of freedom.

luggage is delivered to your home tomorrow), the scores are still negative, but do not differ significantly from the baseline.

Table 4, on the other hand, shows far less severe negative responses among males to the attractive service provider. Only when the attractive service provider offers compensation does the EEG index deviate from the baseline to a significant extent. In other words, males respond considerably less negatively at the subconscious level when dealing with a more attractive service provider than they do with a less attractive one. This pattern of responses adds credence to the earlier contention that Proposition 2 must be rejected.

When considering the scene-by-scene analyses (Tables 3 and 4), it is clear that the compensation offered by the service provider (I will issue you with a voucher for a free ticket for local travel any time during the next year) leads to a negative subconscious response among male respondents regardless of the physical appearance of the service provider.

Table 5 explores female respondents' responses to individual scenes in the service complaint scenario.

In contrast to the male participants' responses to the less attractive female service provider (Table 3 ), female responses are far less severe (less negative), and the EEG responses do not differ significantly from the baseline in any of the scenes. The same applies to the scene-by-scene analyses when female respondents deal with the more attractive male service provider (Table 6). However, a cursory comparison between the male responses (Tables 3 and 4) and the female responses (Tables 5 and 6) seems to suggest that males respond considerably more negatively than females during every scene.

Table 7 shows that when male respondents 'interact' with a female service provider, the EEG responses to the less attractive service provider are consistently lower (more negative responses, implying avoidance behaviour) than to
TABLE 5: Female respondents: Less attractive male service provider.

\begin{tabular}{lllll}
\hline Scene & EEG index & $\boldsymbol{t}$-value & $\boldsymbol{p}$-value & $\boldsymbol{d f}$ \\
\hline Explanation & -0.33 & -1.39 & 0.15 & 17 \\
Accept blame & -0.04 & -1.52 & 0.91 & 17 \\
Apologising & -0.25 & -1.26 & 0.38 & 17 \\
Resolution & -0.07 & -1.91 & 0.80 & 17 \\
Compensation & 0.10 & 0.50 & 0.63 & 17 \\
Appreciation & 0.33 & 1.33 & 0.20 & 17 \\
\hline
\end{tabular}

EEG, electroencephalography; $d f$, degrees of freedom.

TABLE 6: Female respondents: More attractive male service provider.

\begin{tabular}{lllll}
\hline Scene & EEG index & $\boldsymbol{t}$-value & $\boldsymbol{p}$-value & $\boldsymbol{d f}$ \\
\hline Explanation & -0.10 & -0.59 & 0.57 & 17 \\
Accept blame & -0.36 & -1.63 & 0.12 & 17 \\
Apologising & -0.20 & -0.74 & 0.47 & 17 \\
Resolution & 0.11 & 0.40 & 0.69 & 17 \\
Compensation & 0.12 & 0.56 & 0.58 & 17 \\
Appreciation & 0.18 & 1.01 & 0.32 & 17 \\
\hline
\end{tabular}

EEG, electroencephalography; $d f$, degrees of freedom.

the more attractive service provider (indicated by the positive scores in the differences column), except for the compensation scene (negative) and the appreciation scene (which is neutral). The positive scores in the difference columns of Table 7 imply that the subconscious scores with the more attractive service provider are superior to those of the less attractive service provider. This result provides evidence in support of the 'what is beautiful is good' premise at the subconscious level.

Although it was not specifically addressed in this study, one can speculate that the negative difference $(-0.20)$ between the attractive service provider and the less attractive service provider in the compensation scene seems to suggest that male respondents may experience the attractive service provider as insincere (cf. Estelami \& De Maeyer 2002). Insincerity (or the absence of authenticity) has been shown to impact negatively on how complaining customers experience a service encounter (Hennig-Thurau et al. 2006). Another possible explanation may be that the compensation offered by the service provider may be regarded as inappropriate, given the relatively minor nature of the failure, and that may lead to feelings of guilt (Cheng et al. 2015:838). Smith, Bolton and Wagner (1999) have demonstrated that complaining customers prefer service recovery efforts that are commensurate with both the type and the magnitude of the failure.

When female respondents 'interact' with male service providers, five of the six scenes are positive (Table 8). The positive scores in the difference columns of Table 7 imply that the subconscious scores for the more attractive service provider are superior to those for the less attractive service provider. This result provides evidence in support of the 'what is beautiful is good' premise at the subconscious level.

The negative difference $(-0.32)$ between the subconscious responses when the attractive service provider accepts blame for the service failure (-0.36) compared with the less attractive service provider $(-0.04)$ again raises the question of perceived insincerity. However, when service recovery does take place 
TABLE 7: Male respondents: A comparison of electroencephalography responses to attractiveness of female service provider.

\begin{tabular}{|c|c|c|c|c|c|c|}
\hline Scene & $\begin{array}{l}\text { EEG index less attractive } \\
\text { provider }(A)\end{array}$ & $\begin{array}{l}\text { EEG index more attractive } \\
\text { provider (B) }\end{array}$ & Difference score $\uparrow(B-A)$ & $t$-value & $p$-value & $d f$ \\
\hline Explanation & -0.54 & -0.37 & +0.17 & 0.53 & 0.61 & 16 \\
\hline Accept blame & -0.86 & -0.35 & +0.51 & 1.13 & 0.28 & 16 \\
\hline Apologising & -0.46 & -0.42 & +0.04 & 0.12 & 0.91 & 16 \\
\hline Resolution & -0.39 & -0.25 & +0.14 & 0.40 & 0.69 & 16 \\
\hline Compensation & -0.41 & -0.61 & -0.20 & -0.81 & 0.43 & 16 \\
\hline Appreciation & -0.37 & -0.37 & 0.00 & 0.01 & 0.99 & 16 \\
\hline
\end{tabular}

$\mathrm{EEG}$, electroencephalography; $d f$, degrees of freedom.

$\dagger$, A positive sign in this column indicates that the attractive service provider's EEG scores are superior to those of the less attractive service provider.

TABLE 8: Female respondents: A comparison of electroencephalography responses to attractiveness of male service provider.

\begin{tabular}{|c|c|c|c|c|c|c|}
\hline Scene & $\begin{array}{l}\text { EEG index less attractive } \\
\text { provider (A) }\end{array}$ & $\begin{array}{l}\text { EEG index more attractive } \\
\text { provider (B) }\end{array}$ & Difference score $\dagger(B-A)$ & $t$-value & $p$-value & $d f$ \\
\hline Explanation & -0.33 & -0.10 & +0.23 & 0.91 & 0.38 & 17 \\
\hline Accept blame & -0.04 & -0.36 & -0.32 & -0.81 & 0.43 & 17 \\
\hline Apologising & -0.25 & -0.20 & +0.05 & 0.15 & 0.88 & 17 \\
\hline Resolution & -0.07 & 0.11 & +0.18 & 0.57 & 0.57 & 17 \\
\hline Compensation & -0.10 & 0.12 & +0.22 & 0.06 & 0.95 & 17 \\
\hline Appreciation & -0.33 & 0.18 & +0.51 & -0.46 & 0.65 & 17 \\
\hline
\end{tabular}

EEG, electroencephalography; $d f$, degrees of freedom.

$\dagger$, A positive sign in this column indicates that the attractive service provider's EEG scores are superior to those of the less attractive service provider.

(explanation, apologising, resolution, compensation and appreciation), female respondents seem to experience the service recovery actions more positively when the service provider is relatively attractive than when the service provider is less attractive.

\section{Cognitive measurement}

To explore further the 'attractiveness hypothesis', an attempt was made to measure the respondents' rating of the encounter at the conscious level. A five-point Likert scale was used to measure responses to the question: 'If you were the passenger in this video, how satisfied would you be with the way your complaint was handled?' The mean score for the female subsample when rating the less attractive male service provider was 4.37; for the more attractive service provider, it was 4.27. The difference was not statistically significant $(p>0.05)$. When the males were asked the same question, the mean scores were 3.62 (less attractive service provider) and 3.90 (more attractive service provider). Again the difference was not statistically significant $(p>0.05)$. Thus at the conscious level, it appears as if attractiveness does not play a role in how complaining customers perceive the service recovery interaction, regardless of the gender of the respondent. At the conscious level, there is thus no support for the 'attractiveness hypothesis'. However, at the subconscious level, it is apparent that males and females do indeed differ in their responses to more attractive and less attractive service providers in a customer complaint situation. Female respondents were far less likely to respond negatively to the less attractive male service provider than the male respondents' inclination towards the less attractive female service provider.

The result of the pencil-and-paper test (conscious measurement) raises two important issues. Firstly, it appears as if males suppress their negative responses to service failure in general, but their negative emotional responses to less attractive service providers in particular. The second is the question of social desirability bias in consumer responses to customer complaint and service recovery situations.

\section{The contribution of this study}

The study makes a theoretical contribution to our understanding of service failure and recovery in general. At a global level, almost all the measurements revealed a consistent pattern of negative neuro-physiological responses (negative EEG scores) to the service failure and complaint situations, regardless of the gender of the service provider, regardless of the attractiveness or otherwise of the service provider, and almost regardless of the actions the service provider took to address the complaint. More attractive service providers did, however, solicit lower negative responses than the less attractive ones, but they were still negative.

Another theoretical contribution is that there is evidence that participants suppressed their true feelings about the hypothetical service encounter when asked to evaluate cognitively their satisfaction with the service recovery outcome. Their responses to the Likert-type question were neutral, while their subconscious responses told a different story.

The empirical results also showed a gender effect. At the subconscious level, males were considerably harsher on the less attractive service provider in the service recovery situation than they were with the prettier service provider but they would not admit to that at the cognitive level.

It must be noted that the compensation offered by the service provider (I will issue you with a voucher for a free ticket for local travel any time during the next year) led to a negative subconscious response among male respondents, regardless of the physical appearance of the service provider. This could be due to the fact that the male respondents feel that, if the service provider accepts responsibility, offers an explanation, 
apologises and resolves the complaint, compensation is not necessary; and so they may experience uncomfortable emotions such as guilt due to the relative minor nature of service failure and respond very negatively to the proposal.

The underlying premise of this study was the contention that our understanding of consumer decision-making and consumer behaviour can be enhanced by exploring the role of information that the consumer does not consider rationally or even think about. The failure to incorporate subconscious information-processing in research has led to spectacular research failures in recent times. The so-called 'pollsters' were completely wrong in predicting the outcomes of both the 2016 American presidential election and Britain's referendum on leaving the European Union. The pollsters measured their respondents' cognitive evaluation only and ignored their emotional feelings when making their voting decisions.

It is against this background that this study used a data collection method (neuro-physiological research) that collects data on responses that are not under the direct control of the central nervous system. The benefit of using neurophysiological methodologies in consumer research is aptly described by Telpaz, Webb and Levy (2015:511): '.... neuroscience can reveal information about consumer preferences that is unobtainable by conventional methods'.

It is in this context that this study makes several contributions. One is a contribution at a methodological level. As Bagozzi et al. (2000) point out, much of the reported research on emotional and subconscious consumer responses is limited because subjects are often prompted to anticipate their affective responses rather than their 'natural' responses. Natural, unbiased responses are of importance to service managers because a fair amount of mental processing is at the subconscious level (Uleman \& Bargh 1989). As a result, consumers often think in an automated manner, and many motivations and behaviours are not consciously 'controlled'. Due to the influence of these subconscious processes, even consumers themselves are often not aware of the reasons for some of their reactions.

The most important advantage of neuro-physiological observation is that subjects do not know that their subconscious responses are being measured, and they are unable to adjust their responses at will. The methodology offers an important advantage to researchers when responses to sensitive topics are investigated, especially when those responses might be contaminated by stereotyping or social desirability bias (Greenwald \& Banaji 1995). Neuro-physiological measurement also overcomes problems such as respondents' inability to recall past events or behaviours.

\section{Conclusion}

In summary, both the GSR and EEG results reported in this study suggest that, at the subconscious level, there is evidence in support of the 'what is beautiful is good' premise in a non-confrontational service failure and recovery situation. The results also provide evidence that, at the subconscious level, males and females respond differently to the relative attractiveness of the service provider in a nonconfrontational service failure and recovery situation. In other words, there appears to be support for the gender effect at the subconscious level.

\section{Managerial implications}

The results of this study demonstrate that, in a service failure and recovery situation, consumers respond differently at the subconscious level to service providers, depending on how attractive the service provider handling the complaint is. This is so despite the fact that at the conscious level no differentiation is apparent.

It is also apparent that, at the subconscious level, males respond more negatively to service failure and recovery than do females. These negative responses are particularly severe when they are interacting with a less attractive service provider. This is so despite the fact that the service provider accepts blame for the service failure, apologises and recovers the situation.

This result may be problematic for managers of service organisations. On the one hand, they are under pressure from social activists such as Wolf (2012) who decry what they see as unfair discrimination based on 'lookism'. And it is not only females who suffer from this bias. More attractive male employees with an 'above-average appearance', in a study she cites, earn on average $5 \%$ more than their less attractive counterparts. On the other hand, managers know that dissatisfied customers do respond more favourably to those who are more attractive.

One way to respond to this situation is to deflect attention away from a potential focus on the attractiveness of a service provider who handles a customer complaint. Instead, service providers can tailor their own responses in a manner that nullifies the potential impact of attractiveness. Examples could be the physical environment where complaints are handled. Pleasing décor, soothing music and friendly (nonconfrontational) employees can go a long way to overcome the negative impact of frayed emotions. However, these responses must be experienced as authentic and genuine. So-called 'deep acting' has been suggested as a means of conveying the authenticity of provider responses (HennigThurau et al. 2006).

There is considerable value in a managerial strategy based on the principles of contagion. However, as Söderlund and Julander (2009) point out, this approach will not work in an environment characterised by acrimonious interpersonal relations among co-workers, or by acrimonious interpersonal relations among employees and management. Thus, for contagion to succeed, managers need to broaden their approach to ensure an organisational service climate in which employees can be authentic and genuine in their responses to complaining customers. Arranging for complaining customers 
to interact with satisfied customers who had complained earlier, testimonials from satisfied customers, and case studies of how the airline addressed complaints in the past, may be beneficial.

Regardless of the facial features of individual service providers, their general appearance cannot be neglected. The physical appearance of service providers must reflect respect and consideration for their customers and that calls for proper grooming and a professional dress code that beam the message that they are 'professional' rather than 'sexy'.

\section{Limitations of the study}

A limitation of this study, common to almost all neurophysiological studies, is the relatively small sample size that was studied. Given the prohibitive costs associated with this relatively new method of exploring human responses and data collection, sample sizes tend to be relatively small, which inevitably limits the use of the statistical procedures typically associated with large samples.

A further limitation is that only one broad organisational response to service recovery was investigated: the offending airline accepted blame for the service failure, apologised and offered some compensation. Future research could explore an alternative service provider response such as denying responsibility or placing the blame on the customer. In addition, only opposite-gender responses were considered (males responding to female service providers and vice versa). The subconscious responses to same-gender service providers might be totally different. Another limitation of the study was that assessments of the frontline service provider, such as perceived insincerity, have been ignored.

A further limitation of the study was that the impact of the tone of voice of the service providers was not controlled. Their tone of voice could have confounded the respondents' subconscious responses. Having said that, using a service provider's actual, real-world voice does add a degree of external validity that would have been absent had an alternative option, such as an animated voice, been used.

Another theme of future research is a consideration of the legal limitations in including the physical attractiveness of applicants as a criterion in considering job applications. These limitations leave scope for future research.

\section{Acknowledgements}

The contribution of Rafal Ohme and Michal Matukin, based at the Neurohm Research Laboratory in Warsaw, Poland, to this study is gratefully acknowledged. The author would also like to thank the two anonymous reviewers whose feedback contributed significantly to the development of the final manuscript.

\section{Competing interests}

The author declares that he has no financial or personal relationships which may have inappropriately influenced him in writing this article.

\section{References}

Ahearne, M., Gruen, T.W. \& Jarvis, C.B., 1999, 'If looks could sell: Moderation and mediation of the attractiveness effect on salesperson performance', International Journal of Research in Marketing 16(4), 269-284. https://doi.org/10.1016/S01678116(99)00014-2

Bagozzi, R.P., Baumgartner, H., Pieters, R. \& Zeelenberg, M., 2000, 'The role of emotions in goal-directed behavior', in S. Brown \& B.B. Stern (eds.), The why of consumption: Contemporary perspectives on consumer motives, goals, and desires, pp. 36-58, Routledge, Oxon.

Baker, M.J. \& Churchill, G.A., 1977, 'The impact of physically attractive models on advertising evaluations', Journal of Marketing Research 14(4), 538-555. https:// doi.org/10.2307/3151194

Bar-Tal, D. \& Saxe, L., 1976, 'Physical attractiveness and its relationship to sex-role stereotyping', Sex Roles 2(2), 123-133. https://doi.org/10.1007/BF00287245

Bechel, R.B. \& Churchman, A. (eds.), 2002, Handbook of environmental psychology, Wiley, New York.

Berscheid, E., 1981, 'A review of the psychological effects of physical attractiveness', in G.W. Lucker, K.A. Ribbens \& J.A. McNamara (eds.), Psychological aspects of facial form, pp. e1-e23, Center for Human Growth and Development, University of Michigan, Ann Arbor, MI.

Berscheid, E. \& Walster, E., 1974, 'Physical attractiveness', Advances in Experimental Social Psychology 7(0), 157-215. https://doi.org/10.1016/S0065-2601(08)60037-4

Bitner, M.J., 1990, 'Evaluating service encounters: The effects of physical surroundings and employee responses', The Journal of Marketing 54(2), 69-82. https://doi. org/10.2307/1251871

Bitner, M.J., 1992, 'Servicescapes: The impact of physical surroundings on customers and employees', The Journal of Marketing 56(2), 57-71. https://doi.org/10.2307/ 1252042

Bitner, M.J., Booms, B.H. \& Tetreault, M.S., 1990, 'The service encounter: Diagnosing favorable and unfavorable incidents', The Journal of Marketing 54(1), 71-84. https://doi.org/10.2307/1252174

Boksem, M.A.S. \& Smidts, A., 2015, 'Brain responses to movie trailer predict individual preferences for movies and their population-wide commercial success', Journal of Marketing Research LII, 482-492. https://doi.org/10.1509/jmr.13.0572

Bull, R. \& Rumsey, N., 1988, The social psychology of facial appearance, SpringerVerlag Publishing, New York.

Cacioppo, J.T., 2002, 'Social neuroscience: Understanding the pieces fosters understanding the whole and vice versa', American Psychologist 57(11), 819-831. https://doi.org/10.1037/0003-066X.57.11.819

Cacioppo, J.T., Tassinary, L.G. \& Berntson, G.C., 2000, Handbook of psychophysiology (2nd ed.), Cambridge University Press, New York.

Chaiken, S., 1979, 'Communicator physical attractiveness and persuasion', Journal of Personality and Social Psychology 37(8), 1387-1397. https://doi.org/10.1037/ 0022-3514.37.8.1387

Chebat, J.-C. \& Slusarczyk, W., 2003, 'How emotions mediate the effects of perceived justice on loyalty in service recovery situations: An empirical study', Journal of Business Research 58(2005), 664-673. https://doi.org/10.1016/j.jbusres.2003.09.005

Cheng, Y.-H., Chang, C.-J., Chuang, S.-C. \& Liao, Y.-W., 2015, 'Guilt no longer a sin: The effect of guilt in the service recovery paradox', Journal of Service Theory and Practice 25(6), 836-853. https://doi.org/10.1108/JSTP-12-2013-0296

Dallimore, K.S., Sparks, B.A. \& Butcher, K., 2007, 'The influence of angry customer outbursts on service providers' facial displays and affective states', Journal of Service Research 10(1), 78-92. https://doi.org/10.1177/1094670507304694

DeShields, O.W., Kara, A. \& Kaynak, E., 1996, 'Source effects in purchase decisions: The impact of physical attractiveness and accent of salesperson', International Journal of Research in Marketing 13(1), 89-101. https://doi.org/10.1016/0167-8116(95) 00036-4

Dion, K., Berscheid, E. \& Walster, E., 1972, 'What is beautiful is good', Journal of Personality and Social Psychology 24(3), 285-290. https://doi.org/10.1037/ Personality
h0033731

Dion, K. \& Stein, S., 1978, 'Physical attractiveness and interpersonal influence', Journa of Experimental Social Psychology 14(1), 97-108. https://doi.org/10.1016/00221031(78)90063-X

Eagly, A.H., Ashmore, R.D., Makhijani, M.G. \& Longo, L.C., 1991, 'What is beautiful is good, but ...: A meta-analytic review of research on the physical attractiveness stereotype', Psychological Bulletin 110(1), 109-128. https://doi.org/10.1037/ 0033-2909.110.1.109

Estelami, H. \& De Maeyer, P., 2002, 'Customer reaction to service provider overgenerosity', Journal of Service Research 4(3), 205-216.

Feingold, A., 1992, 'Good-looking people are not what we think', Psychological Bulletin 111(2), 304-341. https://doi.org/10.1037/0033-2909.111.2.304

Friedman, H.S., Riggio, R.E. \& Casella, D.F., 1988, 'Nonverbal skill, personal charisma, and initial attraction', Personality and Social Psychology Bulletin 14(1), 203-211. https://doi.org/10.1177/0146167288141020 
Greenwald, A.G. \& Banaji, M.R., 1995, 'Implicit social cognition: Attitudes, self-esteem and stereotypes', Psychological Review 102(1), 4-27. https://doi.org/10.1037/ and stereotypes', $P$ syc
$0033-295 \times .102 .1 .4$

Gulas, C.S. \& McKeage, K., 2000, 'Extending social comparison: An examination of the unintended consequences of idealized advertising imagery', Journal of Advertising 29(2), 17-28. https://doi.org/10.1080/00913367.2000.10673606

Harris, L.C. \& Ogbonna, E., 2006, 'Service sabotage: A study of antecedents and consequences', Journal of Service Research 34(4), 543-558. https://doi.org/ 10.1177/0092070306287324

Harris, K.E., Grewal, D., Mohr, L.A. \& Bernhardt, K.L., 2006, 'Consumer responses to service recovery strategies: The moderating role of online versus offlin environment', Journal of Business Research 59, 425-431. https://doi.org/10.1016/ j.jbusres.2005.10.005

Hazlett, R.L. \& Hazlett, S.Y., 1999, 'Emotional response to television commercials: Facial EMG vs. self-report', Journal of Advertising Research 39(2), 7-23.

Hennig-Thurau, T., Groth, M., Paul, M. \& Gremler, D.D., 2006, 'Are all smiles created equal? How emotional contagion and emotional labor affect service relationships', Journal of Marketing 70(3), 58-73. https://doi.org/10.1509/jmkg.70.3.58

Hogg, M.A. \& Vaughan, G.M., 2008, Essentials of social psychology, Pearson Education, London.

Jackson, L.A., Sullivan, L.A. \& Rostker, R., 1988, 'Gender, gender role and body image', Sex Roles 19(7/8), 429-443. https://doi.org/10.1007/BF00289717

Joseph, W.B., 1977, Effect of communicator physical attractiveness and expertise on opinion change and information processing, Doctoral dissertation, Ohio State University, Columbus, $\mathrm{OH}$.

Joseph, W.B., 1982, 'The credibility of physical attractive communicators: A review' Journal of Advertising 11(3), 15-24. https://doi.org/10.1080/00913367.1982.106 72807

Kagan, J., 2002, Surprise, uncertainty and mental structures, Harvard University Press, Cambridge.

Kahle, L.R. \& Homer, P.M., 1985, 'Physical attractiveness of the celebrity endorser: A social adaptation perspective', Journal of Consumer Research 11(4), 954-961. social adaptation perspective,
https://doi.org/10.1086/209029

Kamins, M.A., 1990, 'An investigation into the "Match-up" hypothesis in celebrity advertising: When beauty may be only skin deep', Journal of Advertising 19(1) 4-13. https://doi.org/10.1080/00913367.1990.10673175

Kardes, F.R. \& Cronley, M.L., 2000, 'The role of approach/avoidance asymmetries in motivated belief formation and change', in S. Ratneshwar, D.G. Mick and C. Hufman (eds.), The why of consumption: Contemporary perspectives on consumer motives, goal and desires, Routledge Publishing, London.

Kleinke, C.L., 1974, First impressions: The psychology of encountering others, PrenticeHall, Englewood-Cliffs, NY.

Koernig, S.K. \& Page, A.L., 2002, 'What if your dentist looked like Tom Cruise? Applying the match-up hypothesis to a service encounter', Psychology \& Marketing 19(1), 91-110. https://doi.org/10.1002/mar.1003

LaBarbera, P.A. \& Tucciarone, J.D., 1995, 'GSR reconsidered: A behavior-based approach to evaluating and improving the sales potency of advertising', Journal of Advertising Research 35(5), 33-53.

Landy, D. \& Sigall, H., 1974, 'Beauty is talent: Task evaluation as a function of the performer's physical attractiveness', Journal of Personality and Psychology 29(3) 299-304. https://doi.org/10.1037/h0036018

Lazarus, R.S., 1999, Stress and emotion: A new synthesis, Springer, New York.

Lorenzoni, N. \& Lewis, B.R., 2004, 'Service recovery in the airline industry: A crosscultural comparison of the attitudes and behaviours of British and Italian frontline personnel', Managing Service Quality 14(1), 11-25. https://doi.org/10.1108/ 09604520410513640

Lowenstein, G., 2001, 'The creative destruction of decision research', Journal of Consumer Research 28(3), 499-505. https://doi.org/10.1086/323738

Mauss, I.B. \& Robinson, M.D., 2009, 'Measures of emotion: A review', Cognitive Emotion 23(2), 209-237. https://doi.org/10.1080/02699930802204677

McColl-Kennedy, J.R., Patterson, P.G., Smith, A.K. \& Brady, M.K., 2009, 'Customer rage episodes: Emotions, expressions and behaviors', Journal of Retailing 85(2), 222episodes: Emotions, expressions and behaviors', Jour
237. https://doi.org/10.1016/j.jretai.2009.04.002

Mehrabian, A. \& Blum, J.S., 1997, 'Physical appearance, attractiveness and the mediating role of emotions', Current Psychology: Developmental, Learning, Personality, Social 16(1), 20-42. https://doi.org/10.1007/s12144-997-1013-0

Meyers-Levy, J. \& Loken, B., 2015, 'Revisiting gender differences: What we know and what lies ahead', Journal of Consumer Psychology 25(1), 129-149. https://doi. org/10.1016/j.jcps.2014.06.003

Molm, L.D., 2006, 'The social exchange framework', in P.J. Burke (ed.), Contemporary social psychological theories, pp. 24-45, Stanford University Press, Stanford, CA.

Nater, U.M., Abbruzzese, E., Krebs, M. \& Ehlert, U., 2006, 'Sex differences in emotional and psychophysiological responses to musical stimuli', Internationa Journal of Psychophysiology 62(2), 300-308. https://doi.org/10.1016/j.ijpsycho. 2006.05.011

Noble, G., Pomering, A. \& Johnson, L.W., 2014, 'Gender and message appeal: Their influence in a pro-environmental social advertising context', Journal of Socia Marketing 4(1), 4-21. https://doi.org/10.1108/JSOCM-12-2012-0049
Ohme, R., Reykowska, D., Wiener, D. \& Choromanska, A., 2010, 'Application of frontal EEG asymmetry to advertising research', Journal of Economic Psychology 31(5), 785-793. https://doi.org/10.1016/j.joep.2010.03.008

Park, B., 1986, 'A method for studying the development of impressions of real people', Journal of Personality and Social Psychology 51(5), 907-917. https://doi.org/ 10.1037/0022-3514.51.5.907

Paulhus, D.L. \& John, O.P., 1998, 'Egoistic and moralistic biases in self-perception: The interplay of self-deceptive styles with basic traits and motives', Journal of Personality 66(6), 1025-1060. https://doi.org/10.1111/1467-6494.00041

Plassman, H. \& Weber, B., 2015, 'Individual differences in marketing placebo effects: Evidence from brain imaging and behavioral experiments', Journal of Marketing Research 52(4), 493-510. https://doi.org/10.1509/jmr.13.0613

Putrevu, S., 2004, 'Communicating with sexes: Male and female responses to print advertisements', Journal of Advertising 33(3), 51-64. https://doi.org/10.1080/00 913367.2004.10639168

Reingen, P.H. \& Kernan, J.B., 1993, 'Social perception and interpersonal influence: Some consequences of the physical attractiveness stereotype in a personal selling setting', Journal of Consumer Psychology 2(1), 25-28. https://doi.org/10.1016/ S1057-7408(08)80073-3

Rumsey, N., 2008, 'The psychology of appearance: Why health psychologists should do looks', The European Health Psychologist 10(3), 46-50.

Saad, G., 2004, 'Applying evolutionary psychology in understanding the representation of women in advertisements', Psychology \& Marketing 21(8), 593-612. https:// doi.org/10.1002/mar.20020

Sergeant, A. \& Frenkel, S., 2000, 'When do customer-contact employees satisfy customers?', Journal of Service Research 3(1), 18-34. https://doi.org/10.1177/ 109467050031002

Slatten, T., 2011, Emotions in service encounter from the perspective of employees and customers, Unpublished PhD Dissertation, Faculty of Economic Sciences, Karlstad University, Sweden.

Smith, A.K., Bolton, R.N. \& Wagner, J., 1999, 'A model of customer satisfaction with service encounter involving failure and recovery', Journal of Marketing Research, XXXVI, 356-372. https://doi.org/10.2307/3152082

Söderlund, M. \& Julander, C., 2009, 'Physical attractiveness of the service worker in the moment of truth and its effects on customer satisfaction', Journal of Retailing and Consumer Services 16(3), 216-226. https://doi.org/10.1016/j.jretconser.2008.11.008

Spalek, K., Fastenrath, M., Ackermann, S., Auschra, B., Coynel, D., Frey, J. et al., 2015 'Sex-dependent dissociation between emotional appraisal and memory: A largescale behavioral and fMRI study', Journal of Neuroscience 35(3), 920-935. https:// doi.org/10.1523/JNEUROSCI.2384-14.2015

Sundaram, D.S. \& Webster, C., 2000, 'The role of nonverbal communication in service encounters', The Journal of Services Marketing 14(5), 378-391. https://doi. org/10.1108/08876040010341008

Tajfel, H., 1981, Human groups and social categories: Studies in social psychology, Cambridge University Press, Cambridge, UK.

Telpaz, A., Webb, R. \& Levy, D.J., 2015, 'Using EEG to predict consumers' future choices', Journal of Marketing Research 52(4), 511-529. https://doi.org/10.1509/ jmr.13.0564

Tronvoll, B., 2011, 'Negative emotions and their effect on customer complaint behavior', Journal of Service Management 22(1), 111-134. https://doi.org/ 10.1108/09564231111106947

Uleman, J.S. \& Bargh, J.A., 1989, Unintended thought, Guilford Press, New York.

Van Praet, D., 2012, Unconscious branding: How neuro-science can empower (and inspire) marketing, Palgrave Macmillan, New York.

Vartanian, O. \& Mandel, D.R., 2011, Neuroscience and decision-making, Psychology Press, New York.

Venkatraman, V., Dimoka, A., Pavlou, P.A., Vo, K., Hampton, W., Bollinger, B. et al., 2015, 'Predicting advertising success beyond traditional measures: New insights from neurophysiological methods and market response modeling', Journal of Marketing Research, LII, 436-452. https://doi.org/10.1509/jmr.13.0593

Walster, E., Aronson, V., Abrahams, D. \& Rottman, L., 1966, 'The importance of physical characteristics in dating behaviour', Journal of Personality and Socia Psychology 4(5), 508-516. https://doi.org/10.1037/h0021188

Wilson, E.J. \& Sherrell, D.L., 1993, 'Source effects in communication and persuasion research: A meta-analysis of effect size', Journal of the Academy of Marketing Science 21(2), 101-112. https://doi.org/10.1007/BF02894421

Wolf, N., 2012, Vagina: A new biography, Hachette Publishers, New York,

Zaltman, G., 2003, How customers think: Essential insights into the mind of the market, Harvard Business School Press, Boston, MA.

Zaltman, G. \& Zaltman, L.H., 2008, Marketing metaphoria: What Deep metaphors reveal about the minds of consumers, Harvard Business Press, Boston, MA

Zeelenberg, M., Nelissen, R.M.A., Breugelmans, S.M. \& Pieters, R., 2008, 'On emotion specificity in decision making: Why feeling is for doing', Judgement and Decision Making 3(1), 18-27.

Zikmund, W.G., 2003, Business research methods, Thomson-South Western, Mason, OH.

Zurawicki, L., 2010, Neuromarketing: Exploring the brain of the consumer, Springer, New York.

Appendix starts on the next page $\rightarrow$ 


\section{Appendix 1}

Complaint:

Good morning. I have just arrived on flight 221 from New York via London. My luggage is not on carousel 1 as you announced, or on any other carousel for that matter. Can you please establish what happened to my luggage?

Explanation: Good morning. I am sure I will be able to help. Unfortunately, it seems as if your luggage was not placed in the correct aircraft during your connection in London. I do not understand why this happened. Your luggage will only be here in 24 hours' time.

Accept blame: It appears as if our airline is to blame for the problem.

Apologising: I want to apologise unreservedly for the inconvenience we have caused.

Resolution: I will make sure that your luggage is delivered to your home tomorrow.

Compensation: To compensate, I will issue you with a voucher for a free ticket for local travel any time during the next year.

Appreciation: Again, please accept my humble apologies. You are a valued customer of our airline and we value your business. 